\title{
Evaluation of DLC, WC/C, and TiN Coatings on Martensitic Stainless Steel and Yttria-Stabilized Tetragonal Zirconia Polycrystal Substrates for Reusable Surgical Scalpels
}

\author{
Stefano Pini, ${ }^{1}$ Roberto Groppetti, ${ }^{2}$ Claudio Mucchino, ${ }^{3}$ and Valentina Geretto ${ }^{4}$ \\ ${ }^{1}$ SITEIA.PARMA Interdepartmental Centre, University of Parma, 43124 Parma, Italy \\ ${ }^{2}$ Department of Industrial Engineering, University of Parma, 43124 Parma, Italy \\ ${ }^{3}$ Department of Chemistry, University of Parma, 43124 Parma, Italy \\ ${ }^{4}$ CIPACK Interdepartmental Centre, University of Parma, 43124 Parma, Italy \\ Correspondence should be addressed to Stefano Pini; stefano.pini@unipr.it
}

Received 28 February 2013; Accepted 7 April 2013

Academic Editors: S. Bernik, K. L. Bing, H. I. Hsiang, and C.-F. Yang

Copyright (c) 2013 Stefano Pini et al. This is an open access article distributed under the Creative Commons Attribution License, which permits unrestricted use, distribution, and reproduction in any medium, provided the original work is properly cited.

\begin{abstract}
DLC, WC/C, and TiN coated SF 100 martensitic stainless steel and Yttria-Stabilized Tetragonal Zirconia Polycrystal (Y-TZP) surgical scalpels were tested, characterized, and comparatively evaluated with regard to chemical leach, micromorphology, and mechanical properties in order to evaluate their suitability as reusable surgical scalpels. Vickers microhardness (HV), Scratch Hardness Number $\left(\mathrm{HS}_{P}\right)$, and sharpening by grinding and cutting capabilities of all the coated scalpels were deemed appropriate for reusable surgical scalpels. However, coated Y-TZP scalpels demonstrated higher Vickers microhardness than martensitic stainless steel scalpels coated with the same coatings, except DLC coating on Y-TZP substrate that presented less adhesion than the other coatings. Uncoated and coated martensitic stainless steel scalpels presented corrosion and chemical leach when soaked for a defined period of time in a simulant physiological saline solution, while uncoated and coated Y-TZP scalpels did not present these drawbacks. Therefore, DLC, WC/C, and TiN coated SF 100 martensitic stainless steel surgical scalpels are unsuitable as reusable surgical scalpels, limiting their application to disposable scalpels only, as the uncoated ones, despite their higher microhardness and expected longer cutting capability duration. Based on these experimental results, WC/C and TiN coated Y-TZP scalpels can be proposed as candidates for reusable surgical scalpel applications.
\end{abstract}

\section{Introduction}

The disposable surgical scalpel made of martensitic stainless steel is currently the standard tool for soft tissue surgery. A disposable scalpel is convenient as it is supplied individually, sharpened after hardening and tempering, and wrapped in sterile package, with no need for further sharpening and sterilization before use. The main reason behind the introduction of disposable, presharpened scalpels was the elimination of the sharpening operations, which are particularly uneconomical for hospitals, because they need dedicated skilled people and/or expensive precision sharpening equipment. This, in turn, imposes the use of large quantities of disposable knives, forcing hospital to manage the disposal of a large amount of waste scalpels, which fall into the category of special waste and therefore require special disposal procedures and additional cost. On the contrary, the sterilization operation does not represent a problem to the user, since it needs to be implemented anyway in surgery departments for all surgical tools and equipment that are used more than once (pliers, scissors, retractors, etc.). This prompts the need of an innovative surgical scalpel that could be reused several times, without the need for resharpening after each use and that can easily be sterilized on the spot whenever necessary without damaging the quality of the cutting edge. Any increase in the cost of the scalpel and the cost of sterilization and of any additional management required would be compensated by the much lower number of knives purchased and by savings on their disposal. 
The disposable stainless steel scalpels currently in use are unfit for this purpose, because they experience a quick loss of sharpness during use to the extent that a number of cutting items may be needed to perform a single surgical incision. Sharpness is an essential feature in surgical scalpels, because it influences the ability to cut, that is, the intensity of the force necessary to achieve the cutting and the quality of the resulting incision. In fact, in order to achieve minimum bleeding, short healing time, and good aesthetic results, a surgical incision needs to be characterized by features such as regularity, uniformity, and minimum damage to the edges of the cutting groove and absence of tears. In addition, the sterilization operation could damage the surface of the disposable scalpel due to the reduced medium/long term corrosion resistance of the martensitic stainless steel used mainly for economic reasons to reduce the cost of the scalpel.

As an alternative to martensitic stainless steel, diamond may be employed for surgical scalpels: the blade is obtained from a single crystal diamond, which is first cleaved along cleavage planes and then abraded and polished following a precise crystallographic orientation by special microgrinding techniques. The high hardness of diamond guarantees longlasting sharpness, but the resulting scalpel is characterized by moderate resistance to breakage (toughness). In addition, the extremely thin cutting edge resulting from this process is very brittle, and it can be chipped during production and handling. As a result, diamond scalpels require careful handling and incur high costs of production and maintenance [1]. For these reasons, diamond scalpels are mainly used for precision surgical operations only, as in ophthalmic and coronary microsurgery or histology.

Ceramic materials could represent suitable substitutes of diamond, because of their biologic and chemical inertness and good mechanical properties, due to their ionic-covalent bonds. In particular, Yttria-Stabilized Tetragonal Zirconia Polycrystal (Y-TZP) is the most widely used ceramic material for manufacturing of medical devices due to the optimal mechanical properties and the high biocompatibility [2, 3]. In spite of such attractive properties, Y-TZP cannot be employed directly for reusable scalpel manufacturing because of its polymorphism; during the usual sterilization process in humid environment, the surface structure undergoes a phase change from tetragonal to monoclinic; this produces a volume increase and the consequent formation of microcracks which reduce its mechanical properties $[4,5]$.

This work proposes the use of reusable scalpels obtained by applying a hard ceramic coating on a substrate with good mechanical properties. The resulting scalpel has good functional properties without being limited in shape or size, as for the case of a scalpel obtained from a single diamond crystal, and it is therefore suitable to be a candidate as reusable surgical scalpel [6]. Since the possibility of reuse of coated surgical scalpels is related to their capability of maintaining their cutting ability, suitable ceramic materials were chosen as coatings. Ceramic coated cutting tools are already widely employed in the mechanical industry for cutting of both metallic and nonmetallic materials. However, suitable ceramic materials are candidates to be employed also in the biomedical field due to their biologic and chemical inertness, good mechanical properties, provided that they demonstrate their capability to sustain several sterilization cycles without damages. In this work, thin ceramic coatings Diamond-Like Carbon (DLC), Tungsten Carbide/Carbon (WC/C) and Titanium Nitride (TiN) have been deposed on substrates of SF 100 martensitic stainless steel disposable surgical scalpels and special Y-TZP (Yttria-Stabilized Tetragonal Zirconia Polycrystal) surgical scalpels. DLC is a metastable amorphous carbon material with significant $\mathrm{sp}^{3}$ bonding [7]; DLC shares some of the properties of diamond, such as high hardness, high elastic modulus, and chemical inertness, but it can be produced much cheaper [8]; WC/C coating is a variant of DLC coating which contains $\mathrm{W}$ in the diamondlike amorphous-hydrogenated-carbon matrix; WC/C coating shows features such as low friction, high wear resistance, and good adhesion [9]; TiN is an extremely hard ceramic material widely employed as a coating to harden surfaces in various applications [10], including the biomedical ones [11]. All these coatings have good haemocompatibility and are considered safe with regard to cytotoxicity [12-15].

\section{Materials and Methods}

2.1. Preparation of Specimens. The martensitic stainless steel specimens (Figure 1(a)) used in this work are made of $13 \mathrm{wt} \%$ chromium, $0.7 \mathrm{wt} \%$ carbon SF 100 martensitic stainless steel (0.4 mm thickness), sharpened by grinding after hardening and tempering, complying to ISO 7153-1:1991 [16] and ISO $7740: 1985$ [17]. The scalpel also complies to standards ISO 9001:2008 [18] and BS EN 46001:1997 [19]. The scalpels were manufactured by Rotax International Ltd. (Sheffield, United Kingdom) and supplied by Artsana S.p.A. (Grandate, Como, Italy) after sterilization by gamma radiation and wrapping in sterile packaging (60 gsm Kraft paper and Novaflex 30/50 polyester/polyethylene film).

Yttria-Stabilized Tetragonal Zirconia Polycrystal (Y-TZP) ceramic specimens (Figure 1(b)) are made by sintering zirconia $\left(\mathrm{ZrO}_{2}\right)$ powders stabilized with Yttria $\left(\mathrm{Y}_{2} \mathrm{O}_{3}\right)$. The material was supplied by Bettini S.p.A. (Monte Marenzo, Lecco, Italy), and it is compliant to ISO 13356:1997 [20]. Sharpening was performed by a diamond grinding machine and finished by fine diamond paste polishing.

All the coating processes were executed by Lafer S.p.A. (Borghetto di Roncaglia, Piacenza, Italy). Thin DLC coating was applied by CVD technique at temperatures between $90^{\circ} \mathrm{C}$ and $130^{\circ} \mathrm{C}$ to minimize thermal distortion and damage to the substrate. The resulting coating has a thickness in the $2 \div 3.5 \mu \mathrm{m}$ range and can be subjected to a service temperature of up to $350^{\circ} \mathrm{C}$ without experiencing any damage (steam sterilization is commonly carried out at temperatures between $120^{\circ} \mathrm{C}$ and $180^{\circ} \mathrm{C}$ ). WC/C coating was obtained by PVD arc-sputtering technique at temperature below $190^{\circ} \mathrm{C}$, resulting in a layer $1 \div 3 \mu \mathrm{m}$ thick. TiN coating was applied by PVD at a temperature of $520^{\circ} \mathrm{C}$. The SF 100 and Y-TZP surgical scalpels coated with DLC, WC/C, and TiN are shown in Figure 2. 


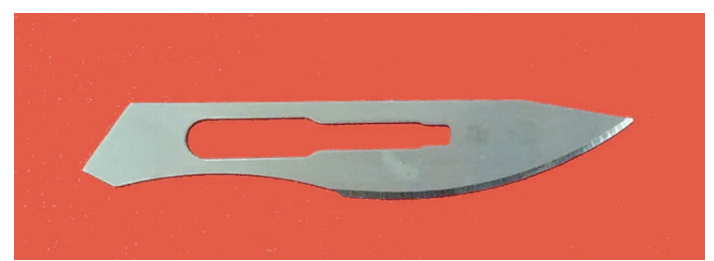

(a)

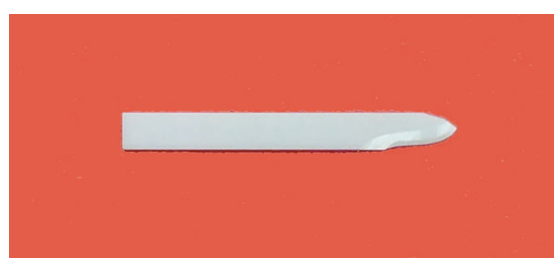

(b)

FIGURE 1: SF 100 martensitic stainless steel (a) and Yttria-Stabilized Tetragonal Zirconia Polycrystal (Y-TZP) (b) scalpels.

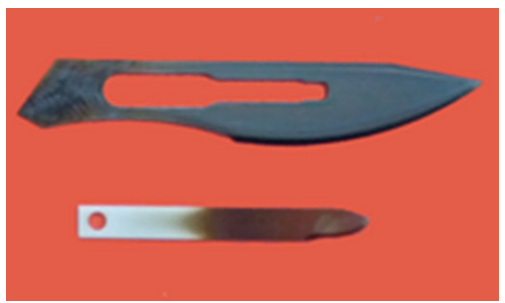

(a)

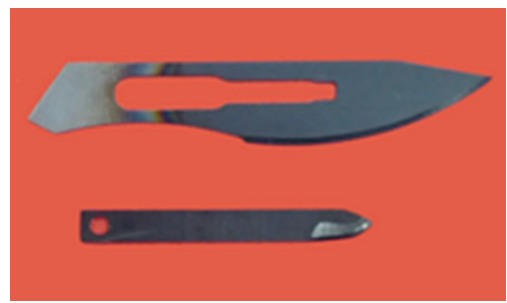

(b)

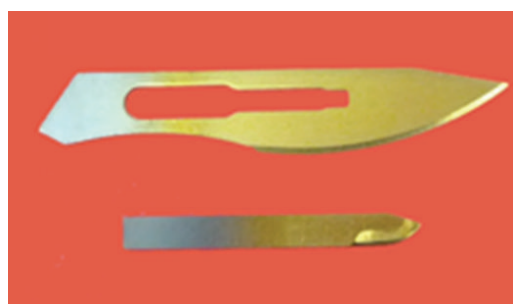

(c)

FIGURE 2: SF 100 and Y-TZP scalpels coated with DLC (a), WC/C, (b) and TiN (c).

2.2. Leaching Procedure. A specific migration test procedure was adopted according to the UE recommendation (90/128/EEC and subsequents) on migration test "when temperature and condition of use are known." The test specimens were masked in order to expose a surface of $62 \mathrm{~mm}^{2}$ and were placed in a plastic (HD-PE) double-sided contact migration cell, ensuring that they would not overlap, and filled with $1.24 \mathrm{~mL}$ of simulant. The simulant chosen was physiological saline solution (a $\mathrm{NaCl}$ (Sigma Aldrich, Italian branch) $0.9 \% \mathrm{w} / \mathrm{V}$ in ultrapure water (Element A10, Millipore, Billerica, MA, USA)). The samples were then thermostated at $37^{\circ} \mathrm{C}$ for 8 hours. Due to the nature of the cell material, the classical procedure of pouring the simulant into a preweighted quartz or platinum capsule and reweight it after the complete drying was impossible. As an alternative the sample itself was preweighted in standard conditions of humidity and temperature $\left(\mathrm{CaCl}_{2}\right.$ filled vessel and $20^{\circ} \mathrm{C}$ for 2 hours) and after the migration test, it was rinsed with ultrapure water, dried and put in the vessel in the same conditions, and then weighted again. The simulant was then sampled and qualitatively analyzed by inductively coupled plasma atomic emission spectroscopy (ICP-AES), (Ultima 2, Jobin-Yvon Horiba, Longjumeau Paris, France) against the blank physiological solution. Since a qualitative analysis was carried out, standard emission lines and conditions, as suggested by the instrument manufacturer, were used.

2.3. Analysis of the Surface Microtopography of Coatings. The morphology of the coatings in the proximity of the cutting edge of the scalpel was observed by means of Scanning Electron Microscopy (SEM) (Jeol SEM JSM-5300) and by Atomic Force Microscopy (AFM) (Digital Instruments AFM Nanoscope III).

Three-dimensional surface microtopography data were acquired on the scalpel side surfaces by means of a prototype
3D stylus-based profilometer (SM RT-150) developed in cooperation with SM S.r.l. (Lombardore, Torino, Italy). Each specimen was acquired 16 times in order to obtain 16 samples for each type of surface. Each resulting dataset consisted of a height map ( $z$ coordinates arranged over a regular $x, y$ grid) sized $128 \times 128$ points, with uniform spacing $d x=d y=$ $12.5 \mu \mathrm{m}$, covering an overall projected area of $1.6 \times 1.6 \mathrm{~mm}$. The height maps were levelled by subtraction of the leastsquares mean plane, and the principal 3D field parameters for surface finish assessment were evaluated, as defined in ISO/FDIS 25178-2:2012 (Table 1) [21].

2.4. Characterization of Coating Mechanical Properties. Mechanical properties of the coatings were evaluated by Vickers microhardness test, in order to measure coating microhardness, and by microscratch test, to measure coating adhesion to substrate.

Vickers microhardness was tested in accordance to EN ISO 6507 1:2005 [22] with an imposed load of $300 \mathrm{~g}$ for coated and uncoated SF 100 stainless steel specimens and $500 \mathrm{~g}$ for coated and uncoated Y-TZP specimens. Load application time was 15 seconds in all tests. Ten indentations were made for each specimen, and the average and standard deviation were obtained for surface hardness.

Microscratch test in accordance to ASTM G 171-03:2009 [23] at increasing load was executed using a computercontrolled scratch tester prototype developed in cooperation with SM S.r.l (Lombardore, Torino, Italy), with pyramidal diamond indenter with $50 \mu \mathrm{m}$ tip radius: $10 \mathrm{~mm}$ scratch length was produced by translating the sample at $10 \mathrm{~mm} / \mathrm{min}$ rate; normal load applied to the indenter was increased at $20 \mathrm{~N} / \mathrm{min}$ rate. The scratched surfaces were examined by optical microscopy and measured by 3D stylus-based profilometry. A quantitative Scratch Hardness Number $\left(\mathrm{HS}_{P}\right)$ was calculated according to the following equation [23]: 
TABLE 1: Definition of the surface parameters evaluated for the morphological analysis of the specimen surfaces (ISO/FDIS 25178-2:2012).

\begin{tabular}{ll}
\hline Symbol & Parameter \\
\hline Sa & $\begin{array}{l}\text { Arithmetic mean height } \\
\text { Root-mean-square height } \\
\text { of the scale-limited surface }\end{array}$ \\
Ssk & $\begin{array}{l}\text { Skewness of the } \\
\text { scale-limited surface }\end{array}$ \\
Sku & $\begin{array}{l}\text { Kurtosis of the } \\
\text { scale-limited surface } \\
\text { Maximum height of } \\
\text { scale-limited surface }\end{array}$ \\
Skk & Core height \\
Svk & $\begin{array}{l}\text { Reduced peak height } \\
\text { Reduced dale height }\end{array}$ \\
\hline &
\end{tabular}

(a)

\section{Definition}

Sa measures the dispersion of heights with respect to the mean surface height. The higher $\mathrm{Sa}$, the rougher the surface.

Sq measures the dispersion of heights with respect to the mean surface height. The higher $\mathrm{Sq}$, the rougher the surface (more sensible than $\mathrm{Sa}$ ).

Ssk measures the symmetry of the surface height distribution curve with respect to its mean value. It is 0 for a symmetric height distribution (e.g. Gaussian) and $\neq 0$ for an asymmetric distribution. It is $>0$ if most heights are below the mean but are counterbalanced by a few regions high above it (hills/peaks); it is $<0$ if most heights are above the mean but are counterbalanced by a few regions well below it (dales/pits).

Sku measures the spikiness of the surface height distribution curve. It is 3 for a roughly Gaussian distribution, $>3$ for spikier distributions, $<3$ for flatter ones.

Sz represents the distance between the highest peak and the deepest pit in the profile.

Sk represents the core (or kernel) roughness of the surface over which a load may be distributed during most of the functional life of the surface. It is a measure of the nominal roughness and may be used to replace $\mathrm{Ra}$ and similar parameters. It is more robust of $\mathrm{Ra}$ especially when localized singularities (e.g., very high peaks or deep pits) may affect the outcome of the more traditional parameters.

Spk measures peak height above the kernel zone. Svk measures valley depth below the kernel zone.

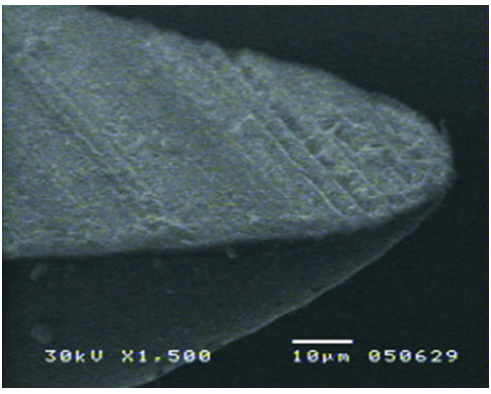

(b)

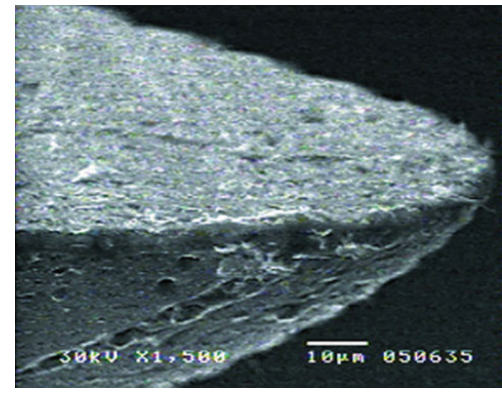

(c)

FIGURE 3: SEM micrographs (1500x) of the tip of scalpels of tempered and sharpened SF 100 martensitic stainless steel: uncoated (a), DLC coated (b), and WC/C coated (c).

$$
\mathrm{HS}_{P}=\frac{P}{A_{\mathrm{lb}}}=\frac{8 P}{\pi w^{2}},
$$

where $P$ is the normal load applied to the indenter, $A_{\mathrm{lb}}$ is the load bearing area, and $w$ is the scratch width.

\section{Results and Discussion}

3.1. Global and Specific Migration. The results of the migration test are reported in Table 2.

As it can be seen the Y-TZP based scalpels gave in any case a negligible result, while weight loss was observed in the steel ones except in the case of the DLC coating. In the martensitic stainless steel case the leaching was so high that a red-brownish powder was found in the migration cell basement. The powder was therefore dissolved in concentrated Nitric Acid (Sigma Aldrich, Italian branch) and then diluted to approximately $6 \% \mathrm{w} / \mathrm{V}$ with ultrapure water for ICP-AES analysis. The qualitative chemical analysis results demonstrated that the powder was constituted of $\mathrm{Fe}$ (probably Iron(III) oxide), while Fe, Cr, Mn, Mo, Ni, and Co were found in the simulant. The lines corresponding to $\mathrm{W}$, $\mathrm{Ti}, \mathrm{Zr}$, Y were negligible, thus enforcing the global migration data.

3.2. Analysis of the Surface Microtopography of Coatings. Figures 3 and 4 show SEM micrographs of tip and cutting edge of the stainless steel scalpels (uncoated and coated with DLC and WC/C). The uncoated sample surface (a) exhibits overall good finish, but regular grooves resulting from the grinding process are present. The DLC coated surface (b) is smoother, although grooves are still visible, together with a few localized particles. The DLC coating preserves the sharpness of the cutting edge, although a minimum thickening can be observed. The WC/C coated sample (c) shows a clear increase in roughness with larger irregularities, resulting in a less neat cutting edge. Digital reconstruction of AFM data (Figure 5) confirms the findings in the case of as produced 


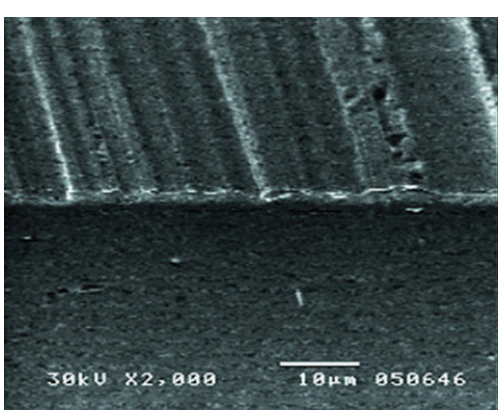

(a)

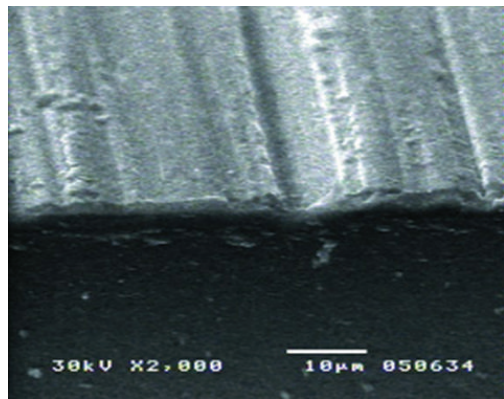

(b)

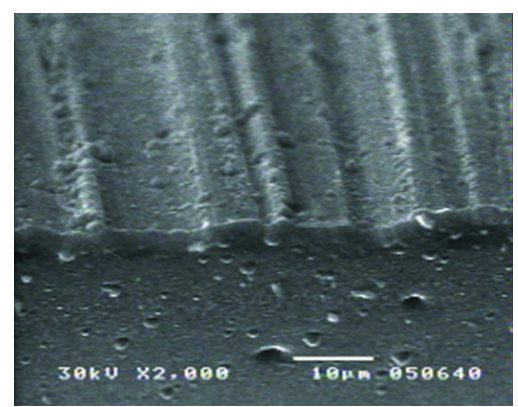

(c)

FIGURE 4: SEM micrographs (2000x) of the cutting edge of scalpels of tempered and sharpened SF 100 martensitic stainless steel: uncoated (a), DLC coated (b), and WC/C coated (c).

TABLE 2: Total migration data (meaningless data were suppressed).

\begin{tabular}{|c|c|c|c|c|c|c|}
\hline & \multicolumn{2}{|c|}{ Weight before (g) } & \multicolumn{2}{|c|}{ Weight after (g) } & \multirow{2}{*}{$\begin{array}{c}\Delta(\mathrm{g}) \\
\mu \\
\end{array}$} & \multirow{2}{*}{$\begin{array}{c}\text { Migration }\left(\mathrm{g} \mathrm{m}^{-3}\right) \\
\mu\end{array}$} \\
\hline & $\mu$ & $\sigma$ & $\mu$ & $\sigma$ & & \\
\hline SF 100 & 0.3552 & 0.0003 & 0.3538 & 0.0002 & 0.0014 & 21.5 \\
\hline SF $100+$ DLC & 0.3649 & 0.0002 & 0.3648 & 0.0004 & - & - \\
\hline SF $100+\mathrm{TiN}$ & 0.3696 & 0.0002 & 0.3682 & 0.0004 & 0.0014 & 21.5 \\
\hline SF $100+\mathrm{WC} / \mathrm{C}$ & 0.3661 & 0.0001 & 0.3653 & 0.0002 & 0.0008 & 12.3 \\
\hline Y-TZP & 0.3528 & 0.0002 & 0.3528 & 0.0002 & - & - \\
\hline Y-TZP + DLC & 0.3852 & 0.0002 & 0.3852 & 0.0002 & - & - \\
\hline Y-TZP + TiN & 0.3795 & 0.0010 & 0.3797 & 0.0003 & - & - \\
\hline $\mathrm{Y}-\mathrm{TZP}+\mathrm{WC} / \mathrm{C}$ & 0.3576 & 0.0002 & 0.3576 & 0.0005 & - & - \\
\hline
\end{tabular}

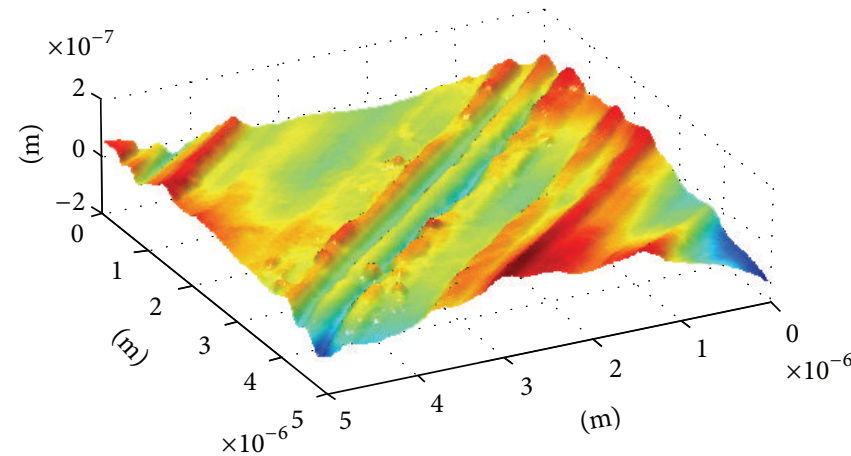

(a)

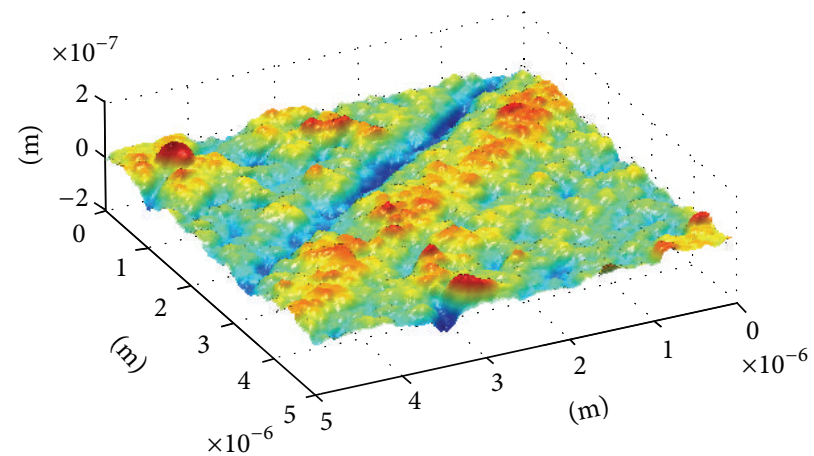

(b)

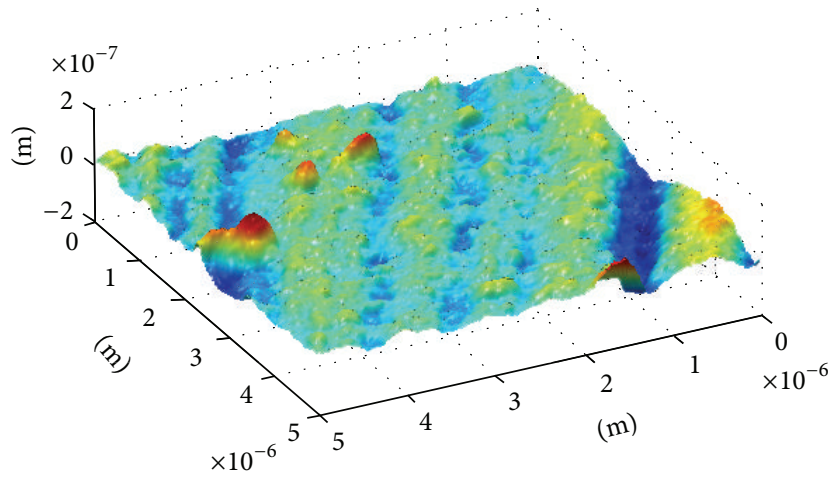

(c)

FIGURE 5: Digital reconstruction of a portion of surface $(5 \times 5 \mu \mathrm{m})$ near the cutting edge of scalpels of polished Y-TZP: uncoated (a), DLC coated (b), and TiN coated (c). 
TABLE 3: Values of the surface parameters for coated and uncoated samples (mean and standard deviation). Parameters are dimensionless, unless otherwise noted.

\begin{tabular}{lccccccccccccccccc}
\hline & \multicolumn{2}{c}{$\mathrm{Sa}(\mu \mathrm{m})$} & \multicolumn{2}{c}{$\mathrm{Sq}(\mu \mathrm{m})$} & \multicolumn{2}{c}{$\mathrm{Sz}(\mu \mathrm{m})$} & \multicolumn{3}{c}{$\mathrm{Sku}$} & \multicolumn{3}{c}{ Ssk } & \multicolumn{3}{c}{ Sk $(\mu \mathrm{m})$} & \multicolumn{3}{c}{ Spk $(\mu \mathrm{m})$} & \multicolumn{2}{c}{ Svk $(\mu \mathrm{m})$} \\
& $\mu$ & $\sigma$ & $\mu$ & $\sigma$ & $\mu$ & $\sigma$ & $\mu$ & $\sigma$ & $\mu$ & $\sigma$ & $\mu$ & $\sigma$ & $\mu$ & $\sigma$ & $\mu$ & $\sigma$ \\
\hline SF 100 & 0.31 & 0.06 & 0.39 & 0.08 & 3.32 & 0.78 & 4.02 & 1.50 & -0.23 & 0.64 & 0.93 & 0.21 & 0.32 & 0.18 & 0.44 & 0.19 \\
SF 100 + DLC & 0.46 & 0.38 & 0.56 & 0.43 & 4.12 & 1.57 & 3.57 & 1.71 & -0.07 & 0.52 & 1.37 & 0.92 & 0.48 & 0.54 & 0.36 & 0.29 \\
SF 100 + TiN & 0.42 & 0.13 & 0.54 & 0.15 & 6.03 & 1.76 & 5.84 & 2.75 & 0.73 & 0.69 & 1.28 & 0.45 & 0.74 & 0.16 & 0.38 & 0.18 \\
SF 100 + WC/C & 0.32 & 0.07 & 0.41 & 0.08 & 4.74 & 1.11 & 5.26 & 1.96 & 0.46 & 0.49 & 0.98 & 0.24 & 0.53 & 0.11 & 0.36 & 0.14 \\
\hline Y-TZP & 0.88 & 0.35 & 1.08 & 0.41 & 6.67 & 1.71 & 3.02 & 0.59 & 0.08 & 0.38 & 2.76 & 0.96 & 1.05 & 0.69 & 0.92 & 0.42 \\
Y-TZP + DLC & 0.76 & 0.42 & 0.94 & 0.48 & 7.55 & 2.53 & 4.19 & 3.79 & -0.18 & 0.58 & 2.33 & 1.21 & 0.87 & 0.65 & 0.80 & 0.37 \\
Y-TZP + TiN & 1.05 & 0.45 & 1.30 & 0.55 & 9.40 & 3.18 & 3.11 & 0.96 & 0.18 & 0.37 & 3.27 & 1.38 & 1.32 & 0.86 & 1.10 & 0.80 \\
Y-TZP + WC/C & 0.68 & 0.27 & 0.85 & 0.33 & 5.98 & 1.63 & 2.90 & 0.29 & -0.21 & 0.29 & 2.12 & 0.79 & 0.56 & 0.18 & 0.94 & 0.54 \\
\hline
\end{tabular}

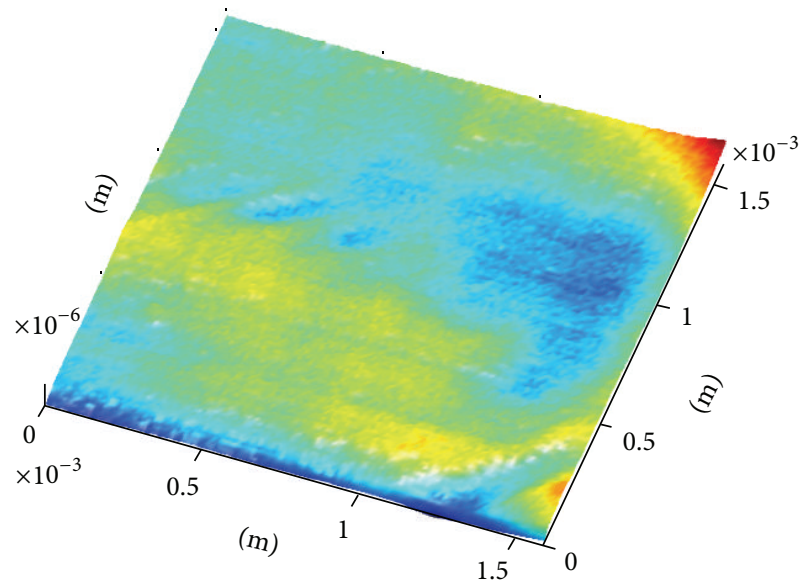

(a)

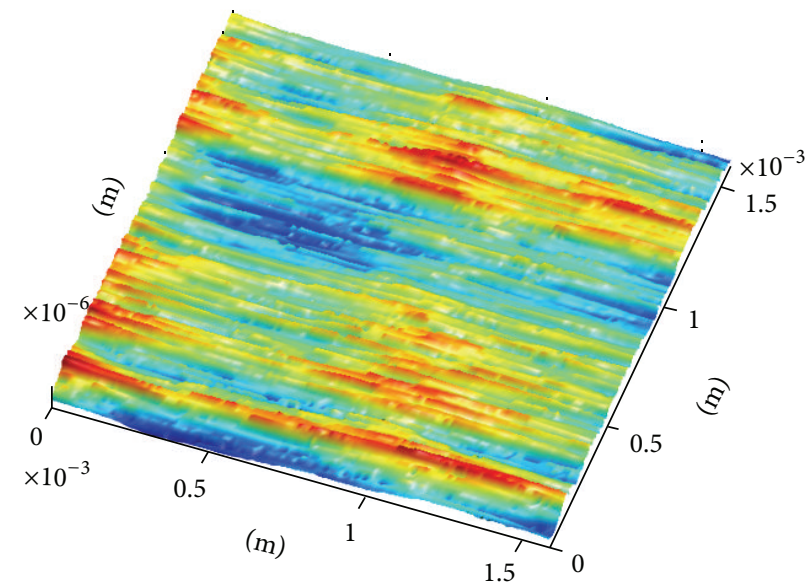

(b)

Figure 6: Digital reconstruction of a portion of the side surface $(1600 \times 1600 \mu \mathrm{m})$ of uncoated scalpels of SF 100 martensitic stainless steel (a) and Y-TZP (b).

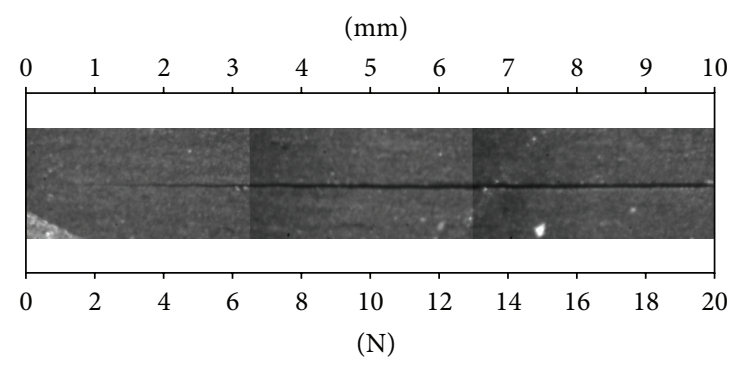

FIGURE 7: Micrograph of the scratch mark on the WC/C coated YTZP sample (100x).

and coated Y-TZP; the DLC coating (b) improves surface finish by partially levelling up peaks and valleys which are found on the original surface (a). The same can be said to some extent about TiN coating (c), although it is less effective in covering the grooves left by the polishing process. None of the coated samples show evidence of cracks and detachments due to poor adhesion of the coating material on the substrate.

The principal parameters for surface finish calculated for the side surfaces of the scalpels are reported in Table 3.

Uncoated and coated Y-TZP scalpels have larger roughness than the SF 100 martensitic stainless steel ones, as shown
TABLE 4: Vickers microhardness for coated and uncoated samples (mean and standard deviation).

\begin{tabular}{lccc}
\hline & $\mu$ & & $\sigma$ \\
\hline SF 100 & & $\mathrm{HV}_{0.3 / 15}$ & \\
SF 100 + DLC & 557.81 & & 50.96 \\
SF 100 + TiN & 705.51 & & 89.2 \\
SF 100 + WC/C & 738.49 & & 56.54 \\
\hline & 654.12 & & 37.81 \\
\hline Y-TZP & & $\mathrm{HV}_{0.5 / 15}$ & \\
Y-TZP + DLC & 1375.38 & & 106.01 \\
Y-TZP + TiN & 1356.82 & & 152.62 \\
Y-TZP + WC/C & 1506.69 & & 100.42 \\
\hline
\end{tabular}

by the average values of arithmetic mean height $(\mathrm{Sa})$ and core height (Sk). This is confirmed by visual observation of the $3 \mathrm{D}$ digital reconstruction of the measured height maps (Figure 6); the surface of stainless steel scalpels (a) is smooth and uniform, while the Y-TZP surface is characterized by sharps peaks and deep valleys that lie along a well-defined orientation. Due to the low surface roughness of the stainless 


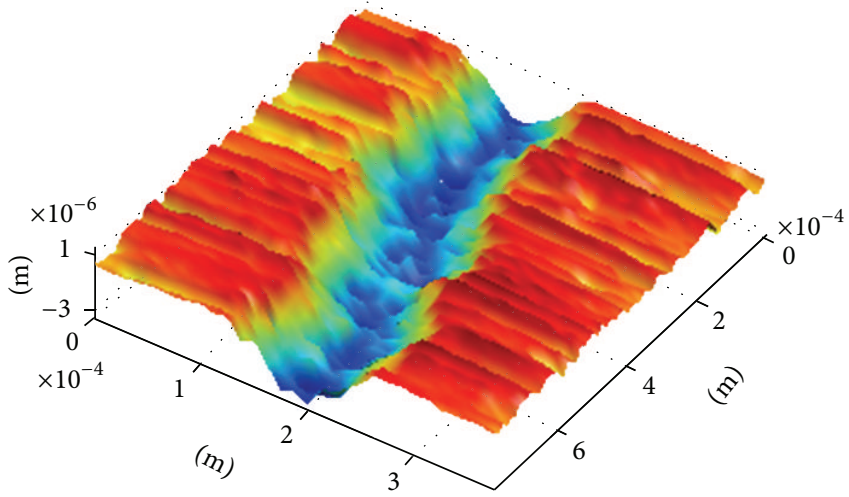

(a)

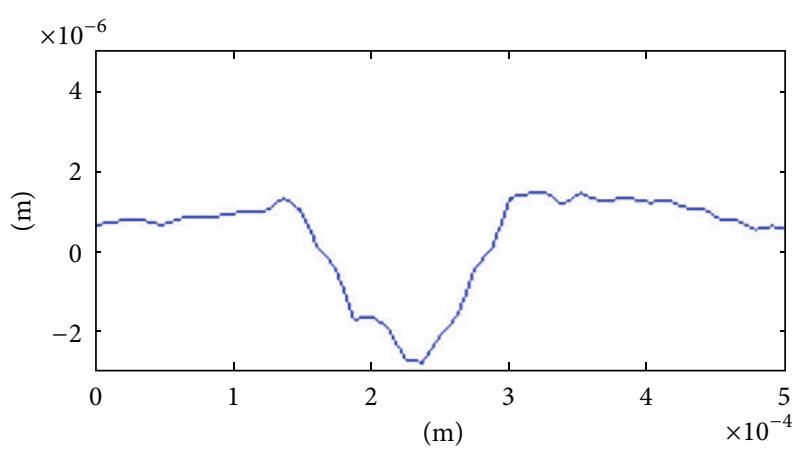

(b)

FIGURE 8: 3D reconstruction (a) and cross section (b) of the scratch mark on the DLC coated Y-TZP sample.

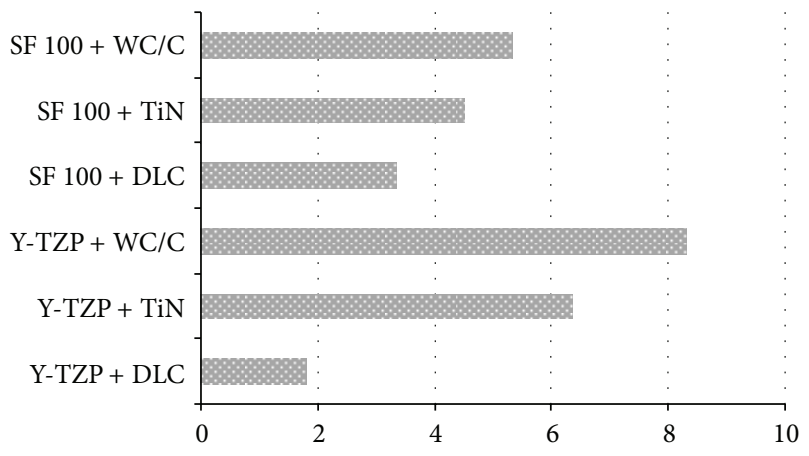

FIGURE 9: Results of $\mathrm{HS}_{P}$ Scratch Hardness Number evaluation.

steel substrate, coating does not provide any additional smoothing of the side surface, as evident from the Sa and Sk values calculated for these surfaces. On the contrary, DLC and $\mathrm{WC} / \mathrm{C}$ coatings on the Y-TZP substrate improve the surface finish by partially levelling up the original peaks and valleys. TiN coating slightly increases the roughness of the original surface.

3.3. Characterization of Coating Mechanical Properties. The Vickers microhardness values for the coated and uncoated samples are reported in Table 4.

In the case of SF 100 martensitic stainless steel scalpels, the application of the coatings noticeably improves surface hardness, as expected. $\mathrm{HV}_{0.3 / 15}$ Vickers microhardness values are approximately half of the $\mathrm{HV}_{0.5 / 15}$ Vickers microhardness values obtained for coatings applied on Y-TZP substrates; this is due to the small thickness of the coating layer which makes microhardness results highly affected by the mechanical properties of the substrate. DLC and WC/C coated YTZP scalpels present lower Vickers microhardness when compared to the uncoated Y-TZP scalpels, while Vickers microhardness is increased with the deposition of TiN. For both substrates, TiN and WC/C coated scalpels show the highest and the lowest microhardness, respectively.
The observation of the scratched surfaces suggests that good adhesion of the coating layer on the steel substrate was obtained in all the cases; none of the tested coatings experienced failure under the range of normal load $(0.1 \div$ $20 \mathrm{~N}$ ) applied in the test. The same result has been obtained for WC/C (see Figure 7) and TiN coatings deposed on Y-TZP substrates. On the contrary, DLC coating deposed on Y-TZP substrate failed at a low normal load, exposing the substrate material on nearly all of the scratch length. This result is confirmed by the 3D digital reconstruction of the scratched DLC coated surface based on height data measured by contact profilometry (Figure 8 ), where the average scratch depth is similar to the thickness of the DLC layer.

Figure 9 shows the average $\mathrm{HS}_{P}$ Scratch Hardness Number calculated for the tested coatings; according to this indicator, the $\mathrm{WC} / \mathrm{C}$ coating exhibits the best behaviour, shortly followed by the TiN coating. As expected, the value of the average $\mathrm{HS}_{P}$ Scratch Hardness Number obtained for DLC coated Y-TZP is even lower than the values of the same parameter calculated for the coated SF 100 martensitic stainless steel samples.

\section{Conclusions and Future Work}

DLC, WC/C, and TiN coatings applied on SF 100 martensitic stainless steel and Y-TZP (Yttria-Stabilized Tetragonal Zirconia Polycrystal) substrates were tested, characterized, and comparatively evaluated with regard to chemical release, micromorphology, and mechanical properties in order to evaluate their application to the manufacturing of reusable surgical scalpels candidates to substitute disposable surgical scalpels. The uncoated and coated SF 100 martensitic stainless steel samples were found to be subjected to corrosion when exposed for a defined time to a simulant physiological saline solution intended to simulate surgery environment; these results, although compatible with the use of such scalpels as disposable surgical tools, because the release of corrosion products is negligible for short periods of time, makes SF 100 martensitic stainless steel coated with the tested coatings unsuitable as reusable surgical scalpels. However, coated YTZP scalpels do not suffer from the same shortcoming. The 
adhesion of the coating layer was found appropriate for all coatings and substrates, besides the DLC coating on Y-TZP substrate. Coated Y-TZP scalpels showed much higher values of Vickers microhardness than coated martensitic stainless steel, due to the harder ceramic substrate.

Based on these results, WC/C and TiN coated Y-TZP appear to be appropriate as reusable surgical scalpels. DLC, WC/C, and TiN coated stainless steel substrates could be appropriate as well, provided that a stainless steel with higher corrosion resistance is chosen as a substrate. Coated stainless steel scalpels would probably be more economical than the coated Y-TZP ones, although such scalpels would have shorter cutting edge life, due to the lower microhardness.

DLC, WC/C, and TiN coated nonstandard martensitic stainless steel scalpels could be used as reusable scalpels, provided that a stainless steel is chosen as a substrate with a corrosion resistance higher than the tested standard SF 100 martensitic stainless steel.

The in-progress and the future work include several topics: the evaluation of the chemical leach, micromorphology and mechanical properties of coated surgical scalpels, and the study of the sharpening process, of the multilayer coating process, of the scalpel life time improvement of stainless steel substrates with higher corrosion resistance but less microhardness, coated with DLC, WC/C, TiN and other multilayered coatings, as soft lubricious coatings, high hardness and low friction coefficient ceramic coatings, over scalpel blade edge and sides [24], and finally also the study of the surgical cutting and wounding mechanism and capabilities and of their effects on healing [25].

Higher corrosion resistance and lower production cost substrates coated by suitable hard and soft coatings would produce reusable surgical scalpels with high biocompatibility, high surface microhardness, and high resistance to corrosion and sterilisation. The future work will address how to avoid burr formation in sharpening due to the lower hardness of the substrate and to identify and define procedure for the appropriate and safe handling and sterilizing of the reusable scalpels following their use, simplifying the manufacturing process of the reusable surgical scalpels.

\section{Acknowledgments}

The authors acknowledge the support of Artsana S.p.A. (Grandate, Como, Italy) for supplying the stainless steel scalpels and Bettini S.p.A. (Monte Marenzo, Lecco, Italy) for supplying the Y-TZP scalpels used on this study, of Lafer S.p.A. (Borghetto di Roncaglia, Piacenza, Italy) for the DLC, $\mathrm{WC} / \mathrm{C}$, and TiN coatings and of SM S.r.l. (Lombardore, Torino, Italy) for the cooperation on the 3D microtopographic analysis. This work was partially supported by the Emilia-Romagna Region (POR FSE 2007-2013).

\section{References}

[1] M. A. Hayat and Y. Zhang, "Care and use of diamond knives," Micron, vol. 29, no. 5, pp. 411-414, 1998.

[2] P. F. Manicone, P. R. Iommetti, and L. Raffaelli, "An overview of zirconia ceramics: basic properties and clinical applications," Journal of Dentistry, vol. 35, no. 11, pp. 819-826, 2007.
[3] C. Piconi and G. Maccauro, "Zirconia as a ceramic biomaterial," Biomaterials, vol. 20, no. 1, pp. 1-25, 1999.

[4] C. B. Azzoni, A. Paleari, F. Scardina, A. Krajewski, A. Ravaglioli, and F. Meschke, "EPR structural study on hydrothermally aged yttria-doped tetragonal zirconia polycrystals," Journal of Materials Science, vol. 28, no. 14, pp. 3951-3956, 1993.

[5] A. Krayewski, A. Ravaglioli, F. Meschke et al., "Ceramic cutting tools for medicine: transformations on the surface of steam treated TSZ-ceramics," Third Euro-Ceramics, vol. 3, pp. 513-518, 1993.

[6] A. Ravaglioli, A. Krajewski, M. Mazzocchi et al., "Ceramic coatings for a highest performance of a zirconia scalpel: cutting tool for surgeons," Materials Engineering, vol. 14, pp. 55-66, 2003.

[7] A. Erdemir and C. Donnet, "Tribology of diamond-like carbon films: recent progress and future prospects," Journal of Physics D, vol. 39, no. 18, article R01, pp. R311-R327, 2006.

[8] J. Robertson, "Diamond-like amorphous carbon," Materials Science and Engineering R, vol. 37, pp. 129-281, 2002.

[9] D. Roth, B. Rau, S. Roth, J. Mai, and K. H. Dittrich, "Large area and three-dimensional deposition of diamond-like carbon films for industrial applications," Surface and Coatings Technology, vol. 74-75, no. 2, pp. 637-641, 1995.

[10] F. S. Shieu, L. H. Cheng, Y. C. Sung, J. H. Huang, and G. P. Yu, "Microstructure and coating properties of ion-plated TiN on type 304 stainless steel," Thin Solid Films, vol. 334, no. 1-2, pp. 125-132, 1998.

[11] J. Park, D. J. Kim, Y. K. Kim et al., "Improvement of the biocompatibility and mechanical properties of surgical tools with TiN coating by PACVD," Thin Solid Films, vol. 435, no. 1-2, pp. 102-107, 2003.

[12] R. K. Roy and K. R. Lee, "Biomedical applications of diamondlike carbon coatings: a review," Journal of Biomedical Materials Research B, vol. 83, no. 1, pp. 72-84, 2007.

[13] V. Krishnan, A. Krishnan, R. Remya et al., "Development and evaluation of two PVD-coated $\beta$-titanium orthodontic archwires for fluoride-induced corrosion protection," Acta Biomaterialia, vol. 7, no. 4, pp. 1913-1927, 2011.

[14] N. Nurdin, P. François, Y. Mugnier et al., "Haemocompatibility evaluation of DLC- and SiC-coated surfaces," European Cells and Materials, vol. 5, pp. 17-28, 2003.

[15] M. I. Jones, I. R. McColl, D. M. Grant, K. G. Parker, and T. L. Parker, "Haemocompatibility of DLC and TiC-TiN interlayers on titanium," Diamond and Related Materials, vol. 8, no. 2-5, pp. 457-462, 1999.

[16] Surgical Instruments, "Metallic materials-Part 1: stainless steel," ISO, 7153-1, 1991.

[17] Instruments for surgery, "Scalpels with detachable bladesfitting dimensions," ISO, 7740, 1985.

[18] "Quality management systems-requirements," ISO, 9001, 2008.

[19] "Specification for application of EN ISO, 9001 to the manufacture of medical devices," BS EN, 46001, 1997.

[20] "Implants for surgery-Ceramic materials based on yttriastabilized tetragonal zirconia (Y-TZP)," ISO, 13356, 1997.

[21] "Geometrical product specifications (GPS)—surface texture: areal-part 2: terms, definitions and surface texture parameters," ISO/FDIS, 25178-2, 2012.

[22] Vickers Hardness Test, “Test method," EN ISO, 6507-2, 2005.

[23] "Standard Test Method for Scratch Hardness of Materials Using a Diamond Stylus," ASTM G 171-03, 2009. 
[24] C. Donnet and A. Erdemir, Tribology of Diamond-Like Carbon Films, Fundamentals and Applications, Springer, New York, NY, USA, 2008.

[25] T. Atkins, The Science and Engineering of Cutting: The Mechanics and Processes of Separating and Puncturing Biomaterials, Metals and Non-Metals, Butterworth-Heinemann, Elsevier, Oxford, UK, 2009. 

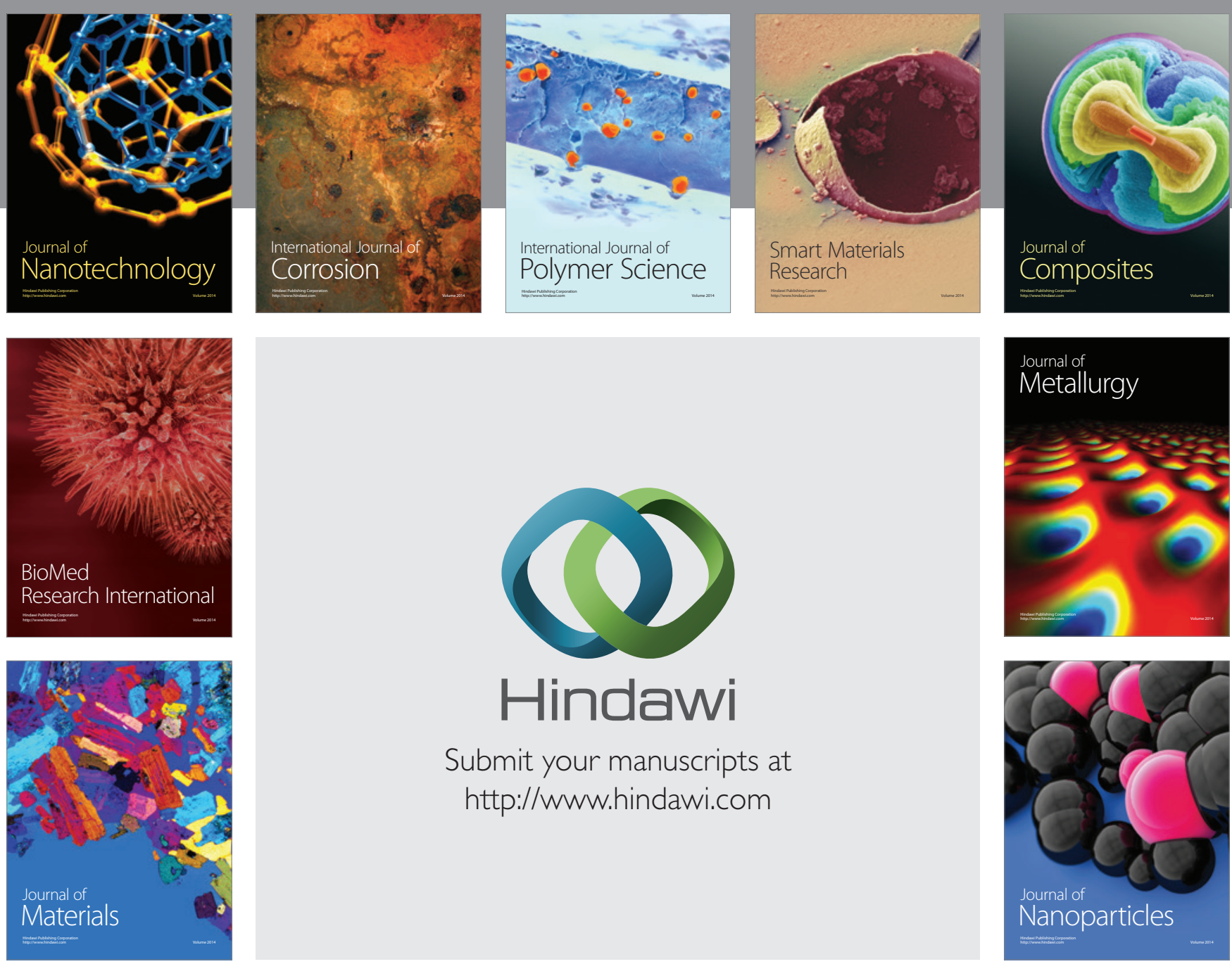

Submit your manuscripts at http://www.hindawi.com
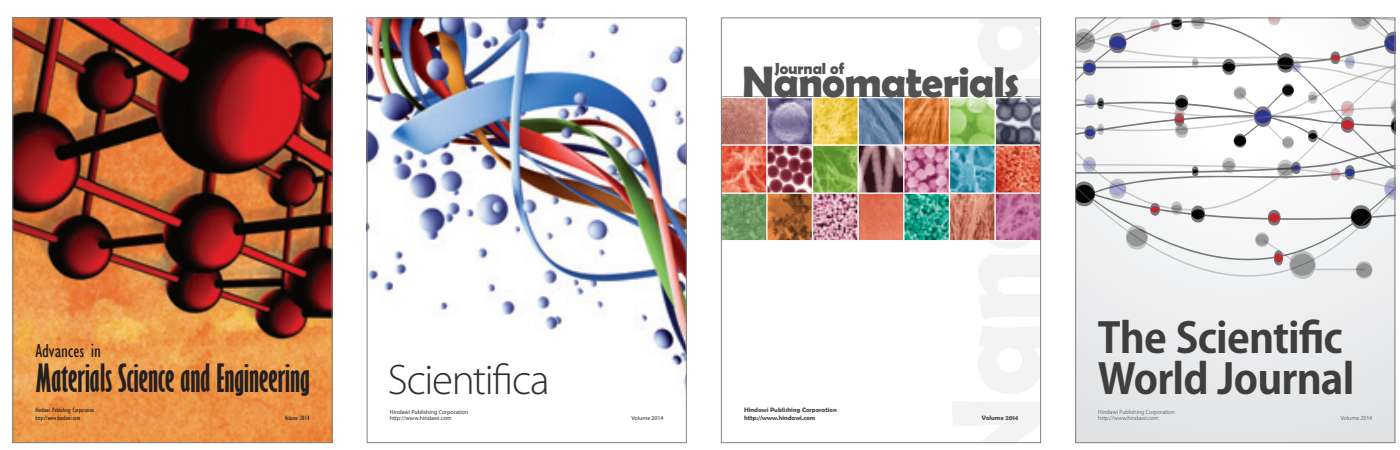

\section{The Scientific World Journal}
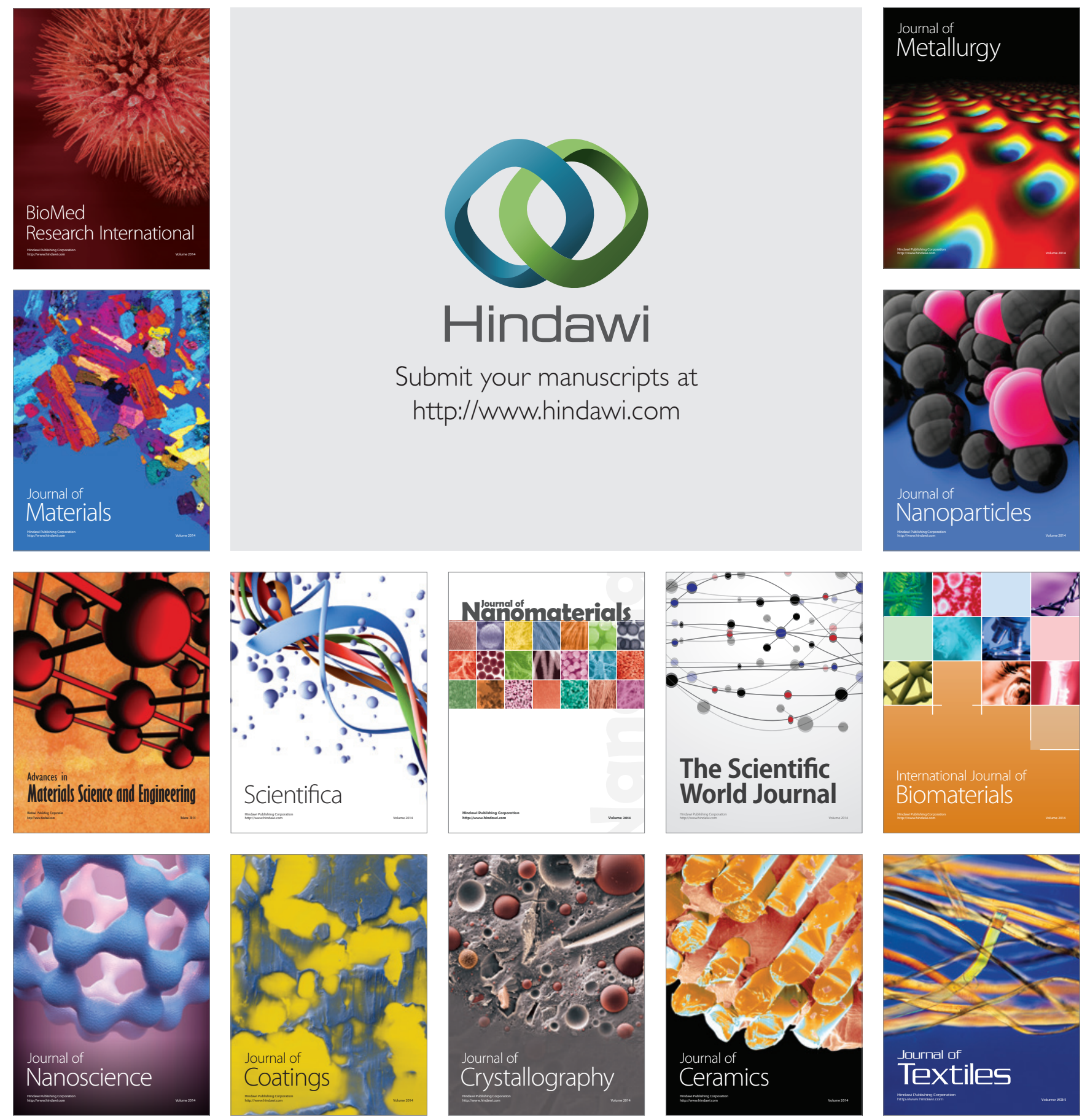